Northern Review

yukoncollege.yk.ca/review

\title{
Addressing Historical Impacts Through Impact and Benefit Agreements and Health Impact Assessment: Why it Matters for Indigenous Well-Being
}

Jen Jones and Ben Bradshaw

\begin{abstract}
Environmental Assessment and related permitting processes have long struggled to identify and mitigate health and well-being impacts associated with resource development, especially in northern, largely Indigenous, jurisdictions. An opportunity to address this governance deficit has seemingly been provided through the growing use of mechanisms such as Impact and Benefit Agreements (IBAs) and Health Impact Assessments (HIA). Their emergence has coincided with a growth in social determinants of health research that recognizes diverse concepts and complex drivers of Indigenous well-being; it is increasingly common for researchers to speak of the "good life" and to recognize health disparities that are based in experiences of poverty, stress, trauma, cultural erosion, and environmental dispossession. Unfortunately, little of this research has come to influence contemporary HIA practices and the content or implementation of IBAs. Missing from these novel governance mechanisms is recognition that present-day resource development is complicated by legacies of colonialism and assimilation policies, which impact Indigenous well-being. In short, what matters to Indigenous communities and what is captured in an IBA or HIA seldom coincide. This argument is supported by evidence of Indigenous participation in the Wishbone Hill HIA in Alaska and the IBA signed in support of the Meadowbank Mine in Nunavut. Given this evidence, this article calls for refinement of governance mechanisms such as IBAs and HIAs in order to better understand and respond to the complexities that inform Indigenous well-being.
\end{abstract}




\section{Introduction}

Mineral exploration and extraction in Canada has long been recognized as a source of economic activity and opportunity, especially in northern jurisdictions. This reputation is understandable; in 2011, a recent peak year, exploration expenditures were $\$ 4.2$ billion across the country, while the total production of minerals, metals, and coal was valued at $\$ 50.9$ billion (Natural Resources Canada, 2014). During such times, the sector has generated substantial wealth for mining firms, governments, servicing companies, employees, and, increasingly, communities proximate to a mine site. For example, in 2007, the owners of the Raglan Mine in northern Quebec issued a payment of $\$ 16.7$ million to Makivik Corporation, much of which was distributed to residents of two Inuit communities in disbursements of $\$ 15,000$ per adult and $\$ 10,000$ per child. This payment was made as per the requirements of the Raglan Agreement, a contract signed in 1995 by the then owners of the mine, Falconbridge, and regional Inuit organizations on whose traditional lands the mine was built.

Since the late 1980s, equivalent agreements, commonly termed Impact and Benefit Agreements (IBAs), have increasingly been established across Canada. ${ }^{1}$ As used in the mining sector, IBAs are negotiated directly between mine developers and Indigenous communities with limited state interference. Their de facto purpose is to deliver enhanced impact mitigation and tangible benefits to communities in exchange for community support of a project (Galbraith, Bradshaw, \& Rutherford, 2007). Routinely, these agreements provide benefits such as payments, employment, and preferential treatment of community businesses; less routinely, IBAs offer a means for would-be impacted communities to influence project design and operation. For example, as a condition of their support for Inco's Voisey's Bay nickel mine, the Labrador Inuit Association secured limits on winter shipping to and from the mine in order to protect winter ice travel by Inuit hunters.

Coincident with the emergence of IBAs, the practice of Environmental Assessment (EA) has evolved, particularly in Canada's North where the process to predict positive and negative impacts of a resource development is now increasingly entwined with land claims. One notable evolution within the practice of EA has been the emergence of Health Impact Assessment (HIA) as a means to better inform health planning and decisions related to resource development; indeed, it is increasingly common for an HIA to be a required component of a proponent's submission to an environmental assessment board (Noble \& Bronson, 2006; Winkler et al., 2013). In other instances, an HIA may be completed alongside an assessment process as has been done by 
the State of Alaska. While HIA is largely a voluntary and an unstandardized process, both Canada and the State of Alaska have produced guidance documents for completing an HIA in relation to a resource development. ${ }^{2}$ In both documents, HIA is promoted as a tool to analyze how a project, such as a mine, might influence the health of local populations (State of Alaska HIA Program [SAHP], 2011; Winkler et al., 2013).

These two novel governance mechanisms, IBAs and HIA, coupled with the growing authority of Indigenous communities as a result of court decisions like the Haida and Taku River Tlingit Supreme Court of Canada decisions of $2004,{ }^{3}$ completed land claims, and shifts in the regulatory obligations and societal expectations of mining firms, have gone some way to rebalance the long, unequal relationship between mining firms and Indigenous communities. At the same time, it is far from clear that the securing of financial benefits through an IBA or the use of HIA to identify and mitigate health impacts has produced net positive health outcomes for Indigenous populations located proximate to mine developments in the Circumpolar North. This concern has been increasingly expressed in scholarship focused on mining, community well-being, and the social determinants of health (SDH) (e.g., Gibson and Klinck, 2006; Parlee, O'Neil, \& Lutsel K'e Dene First Nation, 2007; Bhatia \& Wernham, 2009; Knotsch, Siebenmorgen, \& Bradshaw, 2010; Shandro, Veiga, Shoveller, Scobie, \& Keohoorn, 2011). As applied in an Indigenous context, research on the SDH has illuminated how experiences with poverty, stress, trauma (both directly experienced and via intergenerational transmission), cultural erosion, and environmental dispossession contribute to health disparities experienced by Indigenous populations (Kwiatkowski, Tikhonov, Peace, \& Bourassa, 2009; Richmond \& Ross, 2009; Robertson, 2006). While there is not yet consensus that cultural factors are relevant to measuring and reflecting Indigenous disparities, a considerable amount of recent research indicates that more holistic models of health and attention to social inequalities created through colonialism and assimilationist policies are necessary to address health disparities that continue to be experienced by Indigenous populations (Parkes, 2011; Reading \& Wien, 2013; Richmond, 2009; Sotero, 2006).

We argue herein that one key reason why IBAs and HIA have, to date, struggled to address community well-being concerns around mine development is because IBAs and HIA have insufficiently recognized and responded to the complexities that inform Indigenous understandings of and experiences with health and well-being. Situating and responding to this complexity is not an easy task for IBA negotiators and HIA professionals who are often unequipped with sufficient regional or local data. As well, 
assessment matrices are often linearly defined or ill-suited to capture subtleties or nuanced understandings of experiences with residential or boarding schools, or past mining developments (Jones, Nix, \& Snyder, 2014). And yet, nuanced understanding of Indigenous well-being is precisely what is needed to make IBAs and HIA work. This is especially so with respect to incorporating the impacts of legacies of colonialism and assimilationist policies on present day well-being. ${ }^{4}$

This article aims to stimulate conversation around the use of IBAs and HIA in the management of well-being impacts associated with contemporary mine developments in northern, predominantly Indigenous jurisdictions, paying special attention to the role and impact of experiences with legacies of colonialism. We present two case studies to illustrate some of the challenges of addressing issues of community well-being and to highlight why outcomes of the legacies of colonialism require special consideration in resource assessment and governance mechanisms. The article is presented in three parts. In the next section, some background information is provided on IBAs, HIA, and notions of well-being, especially in an Indigenous context. Though not comprehensive, the reviews provide a common foundation to make sense of two case studies that follow. The first case study focuses on the Inuit Impact and Benefit Agreement signed in support of Nunavut's Meadowbank Mine and the second case study centres on an HIA used to assess health impacts of the Wishbone Hill Mine, a proposed coal mine in Alaska. Finally, in the last section we invite readers to draw on our case studies, and those with which they are familiar, to dialogue on the implications of legacies of colonialism for contemporary governance, and, more practically, conceive of changes to the negotiation and implementation of IBAs and conduct of HIA so that these governance mechanisms might better reflect what matters to Indigenous communities seeking to enhance their well-being.

\section{Background}

This section provides background information on IBAs and HIA, two dominant mechanisms used in the governance of contemporary resource developments to maintain or enhance the health and well-being of northern Indigenous peoples. Following the review of IBAs and HIA, some additional background is provided on notions of well-being as predominantly understood among northern Indigenous peoples. 
Impact and Benefit Agreements

Over the past two decades, Impact and Benefit Agreements (IBAs), and other similarly oriented though differently named agreements between would-be mine developers and Indigenous communities, ${ }^{5}$ have become institutionalized within Canada's mining sector (Bradshaw \& McElroy, 2014). For example, they were used in support of Vale's Voisey's Bay Mine in Labrador, and the Northwest Territories' three operating diamond mines originally developed by BHP Billiton, Rio Tinto, and DeBeers Canada. In some jurisdictions, their institutionalization is a function of negotiated land claims. For example, Article 26 of the Nunavut Land Claims Agreement specifies that an Inuit Impact and Benefit Agreement (IIBA) is required for any major development in the Nunavut Settlement Area that might positively or negatively impact Inuit. In jurisdictions where no such legislation exists, which is the more common circumstance, IBAs have become institutionalized as firms have come to recognize that it is in their commercial interest to address evident gaps in the regulatory process used to permit mine developments. As revealed by Galbraith et al. (2007) in the case of the EA process used in the Mackenzie Valley, these gaps emerge due to the failure of EA processes to consider benefits for locals, provide sufficient project-specific follow-up, and build trust and capacity among stakeholders. Through IBAs, mining firms are attempting to address these gaps and, in particular, accommodate the interests of communities within whose traditional territories they seek to extract resources. By doing so, these firms expect to achieve certainty against local protest and opposition, which generally translates into expedited permitting (O'Faircheallaigh, 2012).

For communities, the rationales for securing a private agreement with a mine developer are well reflected in the term "Impact and Benefit Agreement." The first aim of an agreement is to (further) mitigate the impact of mine construction and operation beyond that achieved through regulatory processes such as EA. This can be achieved through, for example, mutually agreed-upon changes in project design, or enabling community involvement in environmental monitoring. ${ }^{6}$ Given this complementary relationship to EA, Galbraith et al. (2007) view IBAs as "supraregulatory" instruments in that they necessarily exist and function alongside, though are seldom officially a part of, public regulatory systems. The second aim of an agreement is to deliver benefits to locals, such as employment and training, mine business contracts, and direct financial payments. Payments can take a variety of forms, including equity interest, royalties based on profits, royalties based on value of production, royalties based on volume of outputs, and fixed payments (Gibson \& O'Faircheallaigh, 2010). Rather 
than complement public regulatory systems, this second aim of an IBA makes up for these systems' most glaring limitation: though locals inevitably experience a disproportionate share of project impacts, regulatory systems do not privilege locals in terms of capturing project benefits, even where those locals hold special rights. IBAs, therefore, aim to address this shortfall through the delivery of tangible benefits.

Given benefit delivery, IBAs have been widely recognized as an effective mechanism for improving income levels and socio-economic conditions in communities (e.g., Prno \& Bradshaw, 2010). Problematically, however, it is far from evident that IBA-signatory communities are better off with respect to their well-being. Indeed, research on the experiences of IBA-signatory communities has revealed problematic issues, especially associated with new monies and the rotational work schedule, such as increased family stress, substance abuse and crime, and mental health impacts such as depression (Gibson, 2008; Peterson, 2012; Shandro et al., 2011). IBA negotiators are evidently aware of these issues and IBAs increasingly make reference to community well-being as an overarching goal of the agreement; however, few if any IBAs contain concrete provisions that ensure that such issues can be effectively managed. ${ }^{7}$ Though there are an unlimited range of terms that could be included in an IBA, in practice this range has been limited and primarily focused on economic development interests (Siebenmorgen \& Bradshaw, 2011). For too long now, IBAs have been designed to deliver economic benefits with an assumption that these benefits will produce improved community well-being (Knotsch et al., 2010).

\section{Health Impact Assessment}

Health Impact Assessment (HIA) is a voluntary and unstandardized process that is promoted as a tool to analyze how a project, such as a mine, might influence the health of a population. As a relatively recent and still evolving supplement to EA in both Canada and the United States, HIA has enhanced EA practice by specifically addressing diverse issues of health and wellbeing in the assessment of a resource development (Corburn \& Bhatia, 2007; Winkler, 2012). HIA has navigated the limitations of current EAs in which there is tendency to focus on regulatory thresholds and quantitative measurements of risk (Corburn \& Bhatia, 2007). Moving beyond narrowly defined concepts and measurements of health, HIA incorporates a range of information including scientific data, public health expertise, and stakeholder contributions. Using a systematic approach to collect and analyze this data, an HIA can facilitate adjustments to a proposed project to minimize negative 
impacts and maximize positive outcomes (Parry \& Kemm, 2005; State of Alaska HIA Program [SAHP], 2011).

There are no set procedures for conducting an HIA, though best practices offered by mining or impact assessment associations and government-issued reports suggest a series of steps including screening, scoping, assessment, recommendations, reporting and possible monitoring, and evaluation (Douglas, Conway, Gorman, Gavin, \& Hanlon, 2001; MacNaughton \& Hunt, 2009; Parry \& Stevens, 2001). The diversity that may exist in practice is countered with more universal agreement on the underlying purpose of conducting an HIA: to improve decision making, empower local communities, and compel different agencies to consider health at a higher level.

The incorporation of a range of data types from various stakeholders including the public, policy- and decision makers, and industry is aided by HIA's systematic approach and use of health impact categories or health effect categories. This pragmatic approach to informing and assessing decisions and policies regarding human health is common, though it often meets with community resistance, as illustrated in the second case study. This resistance typically stems from the failure of the HIA to capture communities' understandings of their health and hence identify the nuanced ways in which a mine development might generate health impacts. This is particularly germane in the North, where communities, though often small in population, are diverse, and where health inequities experienced by Indigenous peoples persist disproportionately to other parts of Canada and the United States.

A key, albeit voluntary, component of HIA is stakeholder engagement. It is recommended as a best practice to solicit issues or concerns from those most likely to be impacted by a proposed project (Jones et al., 2014; SAHP, 2011; Wernham, 2011). Through the engagement of stakeholders, insight can be gained on a project's perceived impacts on a community or other general project issues of concern (Wismar, Blau, \& Ernst, 2007). Stakeholder engagement also offers an opportunity to solicit historical, cultural, and local knowledge not captured in other demographic or population health statistics. This information is provided through privileging access to local insights, reports, or other grey literature, and through sharing of oral stories. The ability to offer such contributions is often contingent upon past engagement experiences, which suggests that the success of an HIA stakeholder engagement practice relies on effective or perceived "good" engagement. Of course, "good" engagement requires time, and time is not always afforded. Parry and Wright (2003) expand on this, drawing attention 
to a central conflict in HIA; the time needed to build trust and the realities of existing policy and institutional structures seldom coincide, which results in opposing agendas and one or the other foci dominating. If building trust with communities requires time, it is further complicated, particularly in Indigenous communities, where previous experiences with mining have produced negative legacies. Identifying pathways between past experiences and current issues of well-being is inherently difficult, though success may be achieved through an engagement process whereby participants are able to share oral stories, and practitioners can reflect on these experiences and contemplate effective mitigations.

Another key challenge facing HIA stems from its use of tools that make it difficult to document and respond to the complexities of Indigenous health. The predominant approach of HIA is to categorize health impacts, which typically results in the lumping of intergenerational experiences in the catch-all category of social determinants or psychosocial impacts, neither of which is able to specify pathways between the past and present, or facilitate mitigation. Compounding this issue is a practitioner's experience. A practitioner's familiarity with local community dynamics and abilities to facilitate engagement processes that are appropriate and respectful of community norms and expectations are highly individual. As Kearney (2004) argues, what is suggested as HIA best practice and what is actually undertaken seldom coincide.

As a supplement to EA, the advent of HIA has been important for addressing human health and well-being in the assessment of resource development; that said, limitations continue to constrain effective policy and practice responses to identified issues, especially those with historical origins. Consideration of how to address the complexities that inform Indigenous well-being and limitations within current application is required. Failure to do so may result in the perceived need to develop another tool in response to current limitations.

\section{Indigenous Notions of Well-being}

Conceptualizations and perceptions of well-being are diverse and require considerations of who is defining and giving value to the concept (Painter, Fuller, \& Atkinson, 2012). This is of particular relevance given that it is often assessment or governance mechanisms that are contemplating Indigenous understandings of well-being in light of resource development. Broad categories such as First Nation, Metis, or Inuit may help facilitate an understanding of the distinct cultures and languages spoken (and lost), yet do not clearly articulate how peoples in each of the circumpolar regions 
in Canada and the United States interact with their unique environments (Richmond, 2009). Further missing from a categorical depiction of northern peoples is an understanding that health and well-being are not just static concepts but rather a way of being and relating to one's environment.

Well-being is not just another term for health (Painter et al., 2012); rather, well-being is culturally constructed. Indigenous well-being is rich in meaning, and often described through terms such as a good life, connection to land, engagement in traditional activities such as harvesting, practicing Traditional or Inuit Knowledge, sharing food, and being with family (Kral, Idlout, Minore, Dyck, \& Kirmayer, 2011; Paci, 2005; Parlee \& Furgal, 2012). Well-being is often described as being in harmony and balance with oneself and the environment. Through a northern Indigenous lens, well-being can be considered holistic and requires attaining and maintaining a balance between a number of different domains in one's personal and community life. This conceptualization is well reflected in the medicine wheel or Inuuit Qaujimatugansit $^{8}$ (King, Smith, \& Gracey, 2009; Kral et al., 2011). Notable in both concepts is a lack of beginning or end to the different domains in one's personal and community life as each is intrinsic to, and dependent on, one another; thus to have well-being is to have harmony among all aspects of one's life.

Land is not a separate concept to well-being; it is an integral component and is therefore the key site where resource development and Indigenous well-being collide (Christensen \& Grant, 2007; Richmond \& Ross, 2009). Indigenous peoples' relationship to land has been well discussed by many authors (e.g., Kral et al., 2011; Kwiatkowski et al., 2009; Nadasdy, 2002). Noted is that land is not to be owned or considered property. Rather, Indigenous peoples have a relationship of reciprocity with land; land is both embued with and provides for cultural connectivity. This makes evident that well-being is not separable from land (Kral et al., 2011). While life for many northern peoples has changed, their relationship with land nevertheless continues through practices such as harvesting, hunting, and other landbased activities. These practices support the healing and balance, furthering a connection with the landscape in which people live (Cunsolo Willox et al., 2014). Given this consanguinity with land, changes to the landscape or loss of access to land can be a significant determinant of Indigenous wellbeing (Richmond \& Ross, 2009). Alterations to accessing land can result from activities such as climate change, population encroachment or, in the context of this article, resource development.

The complexity of defining and understanding an Indigenous conceptualization and experience of well-being is not limited to a series 
of present day defined factors. Rather, Indigenous well-being must also be understood within the context of a history of cultural erosion, environmental dispossession, and loss of autonomy resulting from colonial and assimilationist policies (Reading \& Wien, 2013; Richmond \& Ross, 2009). Lumba (2005 as cited in Kral et al., 2011) defines colonialism as the "conquest and control of other people's land and goods." In a northern context, this control was exerted through the forced removal of children and their placement in boarding or residential school, the forced relocation of communities, and inherent racism in policies and programs that displaced people from their land, culture, and traditions. Colonial practices are still inherent today and are perpetuated through regulatory processes that fail to consider alternative understandings of concepts like well-being or acknowledge the toll that colonialism and assimilationist policies have had on contemporary Indigenous health (Gracey \& King, 2009; Coulthard, 2014).

Statistics continue to present Indigenous peoples from around the world as facing some of the heaviest health burdens (Smylie, 2009). Indigenous peoples have a life expectancy seven years shorter than non-Indigenous peoples and are more at risk for disease, including diabetes, and heart and respiratory disease (Reading \& Wien, 2013). Indigenous populations, particularly in northern Canada, have higher rates of suicide, and are more likely to experience issues related to mental health and poverty (Lavallee \& Poole, 2010). Of course, these statistics fail to reveal a collective history of deceit and neglect, which has resulted in intergenerational impacts that have exacted a "personal toll on individuals in the form of disease, disability, violence and premature death" (Adelson, 2005, p. S45; Gracey \& King, 2009). In sharing an account of growing up, Alaska Native Harold Napoleon (1996) wrote that current generations are born into shock and are "not culturally the same as their forbearers ... [and today's generations] are linked to the old through their experiences of trauma" (p. 11). The impacts of the past are not isolated to a temporally defined period; rather, the impacts of colonialism continue to resonate in health status, and through policies and programs.

An awareness that well-being is informed, impacted, and determined by legacies of colonialism is becoming more prevalent in recent scholarship focusing on Indigenous health, well-being, and the SDH (Adelson, 2005; Reading \& Wien, 2013). Research on the SDH has done much to illuminate vulnerabilities and disparities. At the same time, no consensus has emerged on a complete list of determinants nor the "mechanisms and contexts through which the SDH influence health" (Reading \& Wien, 2013, p. 2). This has made it difficult to apply research to practice in a meaningful way. While work has begun to develop frameworks that reflect Indigenous knowledge 
systems and trauma (Sotero, 2006), as discussed in the next section, these have not been well-adopted in resource development governance mechanisms (Bartlett, Marshall, \& Marshall, 2012; Cameron, Andersson, McDowell, \& Ledogar, 2010). Practices and experiences of colonialism eclipse concepts of time and place, and legacies continue to resonate for communities. Indeed, they are often embedded in the language and stories shared at community meetings, hearings, and forums organized for the review of contemporary resource developments. This is but one observation that is revealed in a case study, which is reviewed in the next section.

\section{Case Studies}

In this section, evidence from research completed by the authors is drawn upon to demonstrate some limitations of two key contemporary governance mechanisms designed to manage Indigenous well-being impacts associated with resource development, especially with respect to their ability to acknowledge the role of the legacies of colonialism. One case study centres on the Inuit Impact and Benefit Agreement (IIBA) signed in Nunavut in support of the Meadowbank Mine. A second case study offers stakeholder perspectives of an HIA, and more narrowly its stakeholder engagement process, completed in support of a proposed mine in Alaska.

The Meadowbank Mine Inuit Impact and Benefit Agreement

Agnico Eagle Mine's (AEM) Meadowbank gold mine is situated $70 \mathrm{~km}$ north of the Hamlet of Baker Lake (Qamani'tuaq) in Nunavut (see Figure 1). The Inuit community of roughly 1,900 is the third largest in the territory and is the only inland hamlet. The mine was constructed at a cost of $\$ 700$ million (relative to projected revenues of over $\$ 3$ billion over an eight-year lifespan) and began operations in 2010. The construction of the mine followed from the negotiation of an IIBA, finalized in 2006, between the former owners of the property, Cumberland Resources, and the Kivilliq Inuit Association (KIA). The KIA is one of three regional Inuit authorities, which, under the terms of the Nunavut Land Claims Agreement, is empowered to negotiate IIBAs. In other words, rather than negotiate with the hamlet most proximate to the proposed mine site, Cumberland Resources was obliged to secure an agreement with a higher level, regionally-oriented organization as per the institutional arrangements established by Inuit themselves. Following the purchase of the property by AEM in 2007 for $\$ 750$ million, a revised IIBA was negotiated, which was concluded in 2011. 


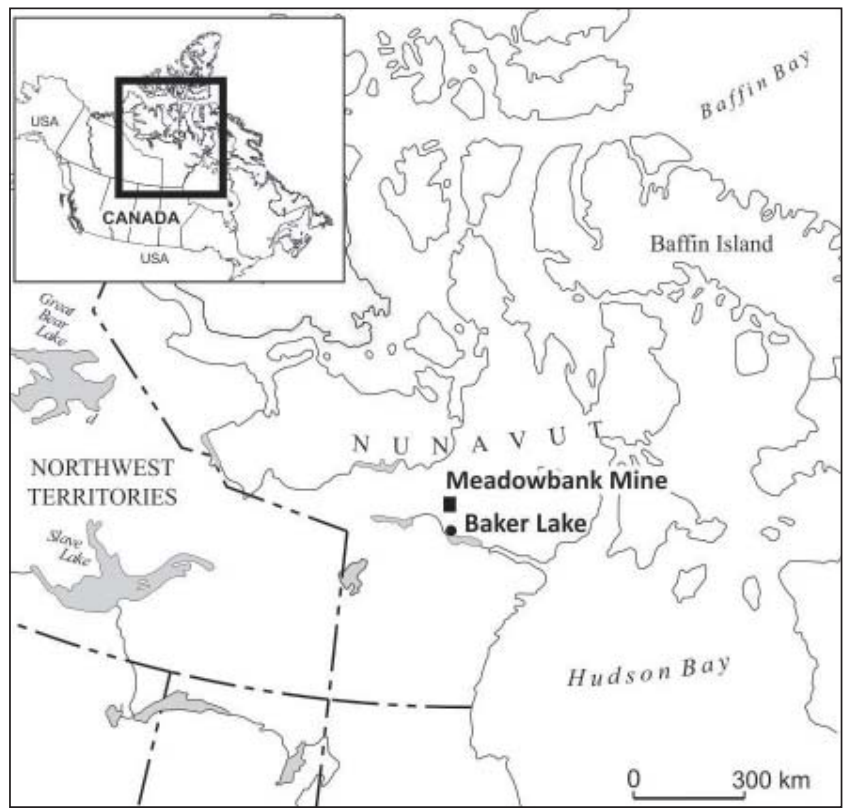

Figure 1. The location of the Hamlet of Baker Lake and the Meadowbank Mine

The IIBA signed between AEM and the KIA is rare in two regards, both of which make it ideally suited to this section's assessment of the ability of an IBA to address community well-being issues: first, it is one of the few company-community agreements that is publicly available (save for its financial chapter, in which payments are specified), which makes it possible to review its content ${ }^{9}$; and second, it is one of the few agreements that explicitly addresses issues of community well-being (what it calls "wellness"). This is done in a chapter titled "Economic, social and cultural wellness," which is the only chapter in the Meadowbank Mine IIBA that privileges the interests of the Hamlet of Baker Lake.

A number of research exercises completed in Baker Lake between 2010 and 2013 inform this case study. These include: two masters theses focused on, respectively, the Hamlet of Baker Lake's general experience with the development and operation of the Meadowbank mine (see Peterson, 2012), and residents' conceptions of community well-being in the context of the mine's development and operation (see Maksimowski, 2014); a knowledge mobilization project with the Hamlet of Baker Lake to respond to residents' questions about the community health implications of mining as revealed in existing scholarship and grey literature (see Barrett-Wood et al., 2012); and 
a co-operative project with the Hamlet of Baker Lake and AEM to develop community wellness indicators that might be used to systematically track change over time (see NIRB, 2013). The execution of these projects has entailed extensive engagement with the Hamlet Council and Baker Lake residents to solicit data and to present draft findings, including the completion of interviews and focus groups with sixty-seven residents between May and July in 2011 and sixty residents between July and September in 2012, two radio phone-in programs and two community workshops in April 2012, a community feast and open house in September 2012, regular meetings with the Hamlet Council, and participant observation. Memoranda of Understanding were established with the Hamlet Council and ethics approval for the various research activities was obtained from both the Nunavut Research Institute and the University of Guelph.

For residents of Baker Lake, their experiences with the development of the Meadowbank Mine have undoubtedly been shaped by, and are arguably a part of, their ongoing transition to Euro-Canadian contact over the nineteenth and twentieth centuries. This transition has been most significant over the past three generations. While a community at the Baker Lake or Qamani'tuaq site was established in the late 1920s with the presence of a Hudson Bay Company trading post and Catholic and Anglican mission churches (and later the RCMP), the majority of Qamanituaqmiut did not reside in the settlement year-round until the 1950s and 60s. Indeed, most Elders in Baker Lake today were born in camps on the land; now many have grandchildren working at the Meadowbank gold mine.

Similar to the rest of Nunavut, the Inuit of Baker Lake have experienced considerable changes with the transition from a nomadic subsistence life to a sedentary mixed economy. Through this transition Western values have been promoted over those practised by the peoples of the region. Residents also live with a history of involuntary relocation, removal of family members for tuberculosis treatment in southern Canada, decreased reliance on traditional foods, and a standard of living below that of populations living in the rest of Canada. In addition, Inuit of Nunavut continue to deal with legacies of colonialism that manifest in relatively high rates of substance abuse and levels of suicide (Cameron, 2011).

Given this history and its associated social issues, many residents of Baker Lake were supportive of the development of the Meadowbank Mine as they expected to generate wealth and improve their well-being through formal employment; others expressed concerns that social issues would only become magnified. Evidence gathered to date supports both views. Indeed, the key finding of Peterson (2012) is that residents' experiences with the 
Meadowbank Mine have been highly varied. In general, those who were in a position of relative advantage before the mine was developed were best positioned to capture new opportunities, especially those with established businesses such as heavy equipment contractors. Opportunities for new, small businesses have been less available. At the same time, the mine has provided opportunities for many individuals to secure employment or improve the terms of their employment. Before the mine, there were few opportunities to work above minimum wage. Many of those jobs required higher levels of education (at least a high school diploma) than many community members had. In addition, the few jobs that existed would only become available when an existing employee retired.

With the arrival of the mine, anyone who wanted to be employed could be. Hence, many residents began to secure regular pay at higher levels than they were accustomed. This outcome is a direct function of the Meadowbank IIBA, which sets targets for Inuit employment and seeks to achieve them through training programs and human resource policies that privilege Inuit. As of 2013, there were 226 Inuit employees at Meadowbank (of a total of 800 employees) with a combined annual payroll of $\$ 19,210,000$; of these, $96 \%$ lived in the Kivalliq region, while $68 \%$ lived in Baker Lake (SEMC, 2013). In focus groups, many of these employees expressed notable pride in terms of their capacity to affect their lives and those of their families, at least financially. For many, this new income has enhanced their quality of life by offering a reliable means to purchase food, hunting equipment, and consumer goods, such as vehicles and entertainment systems. As a result of increased demand, a greater abundance and variety of foods are available at the community grocery stores. While there are still families asking for Inuit food over the local radio, the number of people waiting in line for the monthly food bank has decreased substantially. Wealth in the hamlet is similarly evident in the number of new all-terrain vehicles driving about town and the number of individuals flying south to Winnipeg for shopping. This new wealth has led to a widening financial gap between those benefiting from the mine and those not. Many residents still rely on social assistance or working minimum wage jobs.

Many residents have raised concerns about community social issues that have arisen, or at least become more prominent, since the Meadowbank Mine was developed. When engaged through focus groups, residents regularly identified drug and alcohol use as a concern for community wellness (Maksimowski, 2014). New monies have led to larger and more frequent liquor orders (the hamlet is a liquor-controlled community), and larger Bingo jackpots. The rotational work schedule is also regarded as a source of 
many concerns. For example, leaving the community for two weeks at a time generates challenges for childcare and other family obligations. Arriving home for two weeks with a paycheque has led some to engage in reckless spending of hard-earned income. When an employee lives at the mine for two-week stretches, rumours of infidelity can filter back to their partner or spouse in town and cause domestic issues. These domestic issues have undoubtedly been compounded by work-related fatigue and stress, and even depression, the origins of which are complex (Maksimowski, 2014).

Hence, while the IIBA's employment and preferential contracting provisions have been effective in delivering wealth to many residents of Baker Lake, the IIBA has done little to manage mining's well-known social impacts beyond that which could be expected to occur in a non-IBA signatory community impacted by a mine. This is surprising given that the Meadowbank IIBA includes provisions to monitor and manage hamlet wellness. Specifically, it calls upon AEM to "prepare an annual report on the wellness of the Inuit residents of Baker Lake (the 'Wellness Report and Implementation Plan')." The particular conditions that are to be assessed and reported on are ambitious, including, for example, "the state of the physical and mental health of the Inuit residents of Baker Lake; ... personal and family relationships of the Inuit residents of Baker Lake, including any impacts attributable to employment at a remote work site under a rotational work schedule; ... Inuit culture and traditional practices." For information on these conditions, the annual report is expected to draw upon the annual report of the Kivilliq Socio-Economic Monitoring Committee (SEMC), which has been collecting information about socio-economic conditions in the Kivalliq region since 2009, as well as from other sources such as AEM's own records, data available to AEM from the Hamlet of Baker Lake, and the Nunavut Statistics Bureau.

To date, the tracking of these conditions, let alone the development of adequate responses to those conditions deemed problematic, has been largely ineffectual for a number of reasons. First, the IIBA does not offer sufficient guidance around the organization of community wellness monitoring to ensure that it can be completed. Though the language of the IIBA directs AEM to complete the annual report, it implicates many other players, including the Government of Nunavut, the Hamlet of Baker Lake, the Kivalliq Inuit Association (KIA), and the Kivalliq SEMC. While all of these players have a genuine interest in recognizing and addressing community wellness issues that stem from, or are at least seen to be exacerbated by, mining, their efforts are uncoordinated and seldom sufficient. Second, the SEMC's annual reports, though insightful, have been inconsistent with respect to foci and 
format, making it difficult to systematically track changing conditions within the Hamlet of Baker Lake. Third, the Hamlet of Baker Lake's municipal government, which is governed by locally-elected councillors and a mayor, has struggled to engage its citizens to generate the type of data that would ideally inform annual wellness reporting. This may be due to the fact that the hamlet's normal functions centre on routine tasks such as water delivery, sewage pump-outs, garbage pick-up, and by-law enforcement; identifying community wellness in light of the operation of the Meadowbank Mine may simply be beyond its normal scope. Finally, the aim and substance of the "Implementation Plan" is not defined in the IIBA. It has been left to AEM to craft as it sees fit, which has, to date, simply entailed listing all AEM's initiatives directed towards the health and well-being of employees and their families (e.g., the Employee Family Assistance Program). To be truly effective, community conditions of particular relevance and importance to hamlet residents would need to be tracked in a systematic way, and multiparty (i.e., AEM, the Hamlet of Baker Lake, and Government of Nunavut) management programs developed to address those conditions deemed problematic.

The problem of insufficient community engagement to generate the kind of data needed for the annual Wellness Report and Implementation Plan mirrors a larger, more fundamental limitation of the Meadowbank Mine IIBA as perceived by Baker Lake residents. Though the Hamlet of Baker Lake has undoubtedly been the most impacted by the development of the mine, its role in the negotiation of the IIBA was limited. Consistent with Nunavut's institutional arrangements, the IIBA was negotiated by the KIA, to whom payments flow. For the residents of Baker Lake, they have served to add to, rather than ameliorate, historical processes of disempowerment. Given what we know about self-control and empowerment as a social determinant of health (Richmond and Ross, 2009), this suggests that the IIBA, notwithstanding its special attention to issues of community wellness, is undermining community wellness through its institutional origins and on-going management.

The performance of the Meadowbank IIBA with respect to mitigating community well-being issues associated with mine development is arguably consistent with other IBAs (Knotsch et al., 2010). IBAs are undoubtedly delivering financial benefits to Indigenous signatories and individual members of signatory communities. It is also evident that IBAs are delivering well-being benefits for many of these individuals. However, it is also evident that IBAs are failing to mitigate some of the well-known social issues associated with mine development, which calls into question their net well- 
being benefits for signatory communities. One key finding of Peterson (2012) is that Baker Lake's residents have had highly varied experiences with the construction and operation of the Meadowbank Mine. Problematically, the IIBA does not appear capable of managing this variability. This observation should not be read as a critique of the Meadowbank IIBA, but rather as a call to IBA signatories, governments, consultants, and scholars to think more deeply about how an IBA, in coordination with other governance mechanisms and community health programs, can more effectively manage some of the social issues associated with mining such as increased family stress, substance abuse and crime, and mental health impacts such as depression (Gibson, 2008). Ideally these efforts will be informed by a nuanced understanding of how history informs the well-being of community members and what drives disparities across populations.

\section{The Wishbone Hill Health Impact Assessment}

The State of Alaska has taken the lead in using HIA to assess resource development projects. Recognizing the need to provide capacity support for the implementation of this process alongside an EA, the Alaska HIA Program, a program situated within the Department of Health and Social Services, was developed in 2010. At the onset of the program, local experts, including representatives of the Alaska Native Tribal Health Consortium, local governments, and others, developed a toolkit of best practices for conducting HIA in Alaska. The toolkit concurs with commonly held HIA best practices, suggesting that knowledge from those impacted by a proposed project should be solicited in order to better illuminate possible health impacts and mitigations. Suggested best practices for community consultation are found in a section dedicated to stakeholder engagement.

This second case study draws upon findings from research that was conducted to identify stakeholder perceptions of the stakeholder engagement process completed as part of the Wishbone Hill Mine (WHM) HIA. The HIA was used alongside the EA process for a proposed coal mine located in the Matanuska Susitna (Mat-Su) Valley in south central Alaska (see Figure 2). The Mat-Su Valley is home to both Alaska Native and non-Native citizens, and is the traditional territory of the Ahtna people. The Alaska Native population of the Mat-Su Valley is small compared to the rest of the State of Alaska; only $5.5 \%$ of the total population in the Mat-Su Valley are identified as Alaska Native, of which $28 \%$ live within 10 miles $(16 \mathrm{~km})$ of the proposed mine site (Alaska Department of Health and Social Services [ADHSS], 2012). 


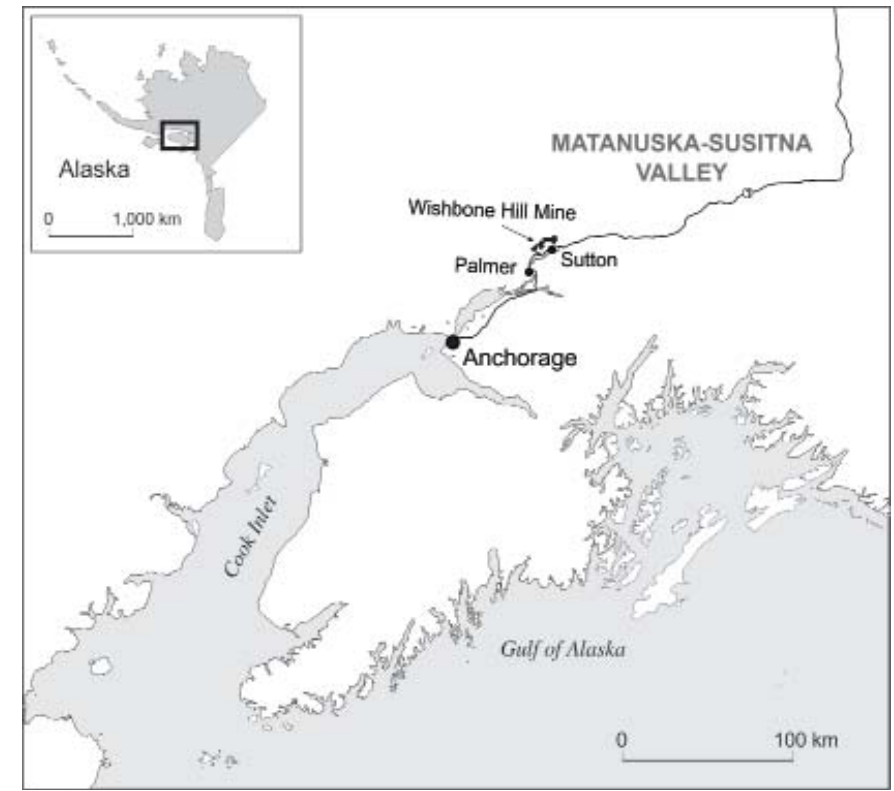

Figure 2. Detail of the Matanuska Susitna Valley and the location of the Wishbone Hill Mine

The research informing this case study was conducted over nine months by this article's lead author, with participant interviews occurring four months after the release of a draft HIA in March 2012. ${ }^{10}$ The research used purposeful sampling to ensure representation from each of five stakeholder groups identified in the draft HIA ${ }^{11}$; participants were recruited from lists provided by community leaders representing each of these groups and were limited to those who had attended at least one of the seven stakeholder engagement sessions organized for the HIA. Identifying these participants was challenging as the draft HIA did not identify the total number of participants invited to the HIA stakeholder meetings, nor did it identify the number of participants representing each of the stakeholder groups. Through key informant interviews, it was determined that these meetings consisted of three to fifteen participants. In all, thirteen interviewees participated, of which three self-identified as Alaska Native. Transcribed verbatim, the halfhour to eighty-minute open-ended semi-structured interviews examined stakeholder perspectives of the WHM HIA stakeholder engagement process and the ability of the draft HIA to capture, reflect, and address health concerns of citizens situated in the impact zones. Questions focused on participants' concepts of health, their experiences with the WHMHIA engagement process, and their views of the ability of the HIA and/or stakeholder engagement 
process to consider or address their understanding of health and well-being (see Jones et al., 2014 for details). In accordance with a research agreement signed with the Chickaloon Village Traditional Council (CVTC) Health and Social Services Department, preliminary research findings were shared with the CVTC Chief and Council, the governing body for the Athna peoples of the Mat-Su Valley. Ethics approval for the research was obtained through the University of Alaska Anchorage Institutional Review Board.

The Mat-Su Valley has undergone significant changes with the arrival of settlers in the early 1900s. However, the changes to the Alaska Native way of life in the area are not necessarily documented in written format. This is similar to many other Indigenous histories and requires researchers to use grey literature, local stories, and personal accounts to piece together events and experiences of the local population as they relate to land and well-being. It is unknown how long the Ahtna people have occupied the Mat-Su Valley, though archaeologists suggest human presence for 5,000 to 7,000 years (www.Alaskool.org, 2004). With the discovery of gold in the late 1800s, the region experienced significant change; due to disease and a high infant mortality rate among the Alaska Native peoples, the population plateaued (www.Alaskool.org, 2004). From the 1930s to the 1950s, the American government established and enforced mandatory education for all Native peoples living in Alaska. Similar to other regions that mandated the forced relocation of communities and the removal of children to be placed in staterun institutions, or that banned the use of traditional language or ceremony, the legacy of boarding schools is evident today in internalized oppression, shame, and intergenerational trauma (Adleson, 2005; Athabascan Nation Chickaloon Village, n.d.; Browne, 2007; L. Wade, personal communications, November 7, 2012).

These previous experiences and relationships with government institutions and mining projects had taken a toll on families. Their experiences, while set in the past, were said to be still impacting them today, and informed their perspectives of the proposed coal mine and its likely impact on their health and well-being. Past experiences with government institutions and mining projects also influenced the trust that participants granted, or rather did not grant, to HIA practitioners and the department hosting the HIA. The issue of past relations with government institutions required that the HIA process attend to issues of trust or mistrust particularly as HIA is a mechanism that requires a relationship with stakeholders in order to gather information on local issues and concerns. Alaska Native participants in the WHM HIA stakeholder engagement process identified their lack of trust as stemming from previous experiences with coal mining in the Mat-Su Valley 
as well as experiences with assimilation policies including boarding school. Participants also expressed doubt that the assessment mechanisms would consider Alaska Native health concerns. This was evidenced through their comments about the mechanism's inability to understand an Alaska Native concept of well-being and recognize the complexities that inform their understanding of well-being.

When asked to describe possible impacts on their well-being as a result of the proposed coal mine, Alaska Native participants did not use language and descriptors that temporally bound perceived impacts. Rather, experiences with previous mining operations and institutional bodies resonated in their comments. Participants shared stories that had been passed from generation to generation and family to family. This information was also provided in written format and offered as additional documentation to the HIA practitioners. When community members perceived that their contributions were not adequately addressed in the draft HIA, and more specifically in proposed mitigations, Alaska Native participants expressed frustration that the lived history of their peoples and intergenerational impacts were once again dismissed. This led participants to question the rationale of the HIA, and suspect that it was just a perfunctory exercise.

It is common for HIA stakeholder meetings to hear Indigenous participants speak about: their connection to, or their relational approach with, land; the role of traditional practices in maintaining well-being; and their experiences with residential or boarding schools. Alaska Native participants identified that similar comments were also shared during the WHM HIA stakeholder meetings. "I don't think people realize it's not just talking about coal mining; it's talking how it impacted your entire family system and the damage that was done and making those connections" (Research Participant). The participants' sharing of stories with HIA practitioners was identified as a means to bring awareness to the connection between experiences of past sickness; racism; family death; forced relocation to boarding schools; loss of culture, language, and traditions; and current issues of health and well-being. Sharing stories of historical experiences and trauma was a way to explain the impact of these experiences on contemporary and even future health. The Alaska Native HIA participants were offering a story that described the pathway from historical experiences through intergenerational trauma to current interactions and relations with mining companies and assessment mechanisms like HIA.

While engagement with stakeholders provides an opportunity to access community-specific and community-relevant information, it can, as demonstrated in the engagement process used for the WHM HIA, face 
challenges of practice as identified by scholars such as Kwiatowski (2011). These include, but are not limited to, the consideration of time and respect for local cultural practices. There was a perception by Alaska Native participants that not enough time was allocated to collecting and documenting Elder contributions. Often presented in story format, these contributions can be lengthy and not always linear:

Elders don't necessarily tell you something straightforward; they talk in circular patterns sometimes. You may have an Elder who will sit there and talk around an issue all the way around it before they come to the centre part of the issue. (Research Participant)

Participants expected or felt it necessary that additional time and opportunities be provided to collect and document information shared by Elders. With this expectation came additional considerations that were not attended to. In addition, for some participants in the room, hearing stories shared by Elders about traumatic experiences with boarding schools or previous mining developments in the region was a first. This resulted in two concerns: that Elders were made to relive trauma, and that some community members experienced trauma by hearing stories for the first time. Research participants expressed concern about the lack of preparation for this by the HIA practitioners.

The CVTC Department of Health and Social Services was aware of potential issues that would arise as a result of the time needed to adequately and respectfully engage Elders and community member and the time offered by the HIA process. To alleviate potential stress and tension, for both community members and the HIA team, the department offered locally constructed Elder ethnographies to the HIA team. The ethnographies were offered as a supplement to missing information and included a documentation of hardships previously experienced, location of traditional gathering and hunting grounds, and the relevance of these contributions to current well-being. Surprisingly for the CVTC, the ethnographies were not used or accepted as complementary documentation to inform the HIA. The lack of recognition for locally generated documentation, in this case placespecific ethnographies, speaks to a larger issue of a perceived bias to use health information founded in Western, reductive, and empirically validated data.

The term "community context" arose in conversation with the research participants as a way to explain the setting or environment in which concerns about well-being were experienced and shared. This context or setting of a 
community is informed by several factors including existing health issues, culture, demographics, local politics, and past experiences of colonial policies and resultant intergenerational traumas. Participants raised concern about the lack of understanding and attention given to context and its contribution to the well-being of CVTC citizens. Alaska Native participants explained that their well-being is inextricably tied to their sense of place and their reciprocal relationship with land. Given that past mining had impacted their traditional hunting grounds and fishing holes, there was genuine concern that new development would further erode their ties to the land and hence impact their well-being. Many interviewed participants, both Alaska Native and non-Alaska Native, expressed frustration that HIA practitioners from away could not adequately grasp this concern and translate it for use and analysis in the draft HIA.

Common to all the perceived limitations of the WHM HIA stakeholder engagement process and resulting draft HIA identified by Alaska Native participants was the lack of attention afforded to historical impacts and the role these impacts have on contemporary well-being. Alaska Native participants believed that this failing was a result of the format through which participants were asked to share information. As suggested earlier, stories told by Elders are not easily measured or categorized, which may have resulted in the scoping out of historical experiences and concerns. Many participants read this scoping out as an intentional erasure of the past and negation of the importance of their history and the continued impacts colonialism has on their people. The lack of attention to impacts of colonialism in the HIA was perceived as a bias of the HIA practitioners. Participants suggested the lack of experience working in Indigenous communities contributed to the practitioners' inability to collect, document, and respond to community-identified issues. Practitioner bias or experience also may inform how comments are documented or weighted. HIA practitioners who are not familiar with research explaining pathways between trauma and wellbeing and/or literature on colonialism as a distal determinant of health are likely to disadvantage the experiences of Indigenous peoples in the HIA. The issue of practitioner skills (or lack of) requires attention as shared stories of intergenerational experiences of trauma, previous experiences with mining development, and restricted or changed access to the healing properties of the land may not find a best fit in the existing health categories of an HIA.

The pragmatic use of health-impacts categories in an HIA, while useful for summarizing findings, was identified as limiting the ability of the mechanism to capture nuanced understanding of Indigenous wellbeing, particularly the connection between historical issues and current 
wellness. This is not to suggest that HIA or other assessment mechanisms should suspend collecting quantifiable data or limit the use of aggregate data found in the form of health demographics and population statistics. However, it is critical that HIAs consider how findings, including baseline information, be informed by alternative forms of knowledge and data so that they continue to have relevance and application in a northern context. These alternative sources include stories, locally developed indicators, and baseline information.

HIA clearly has a role to play in the assessment of resource development in the North, either as a standalone document or part of a larger EA process. The mechanism has the ability to address issues of health and well-being not properly managed by EA. However, as this case study demonstrates, there is a need to consider how HIA might better respond to the legacies of previous mining projects and flawed governance, intergenerational experiences of trauma, and past and ongoing experiences with colonialism.

If they would include the history and what happened, [the HIA Practitioners] may gain a better understanding ... if they showed they cared about what happened in the past and this is why we don't want it to happen again. (Research Participant)

\section{A Call to Action (or at least to converse)}

Given the challenge faced by Environmental Assessment and related permitting processes to identify and mitigate the health and well-being impacts of major resource developments, it has been encouraging to see the growing use of complementary governance mechanisms like Impact and Benefit Agreements (IBAs) and Health Impact Assessments (HIA) in northern jurisdictions. As revealed through our reviews of the Meadowbank IIBA and the Wishbone Hill HIA, however, these mechanisms require further refinement to realize their full potential. Though our review of the cases likely sounded critical, its genuine aim is to stimulate further conversation around the improved use of IBAs and HIA in the management of well-being impacts associated with contemporary mine developments. Undoubtedly, these conversations must involve trying to understand better-and then account for within contemporary governance processes-the complexities that inform Indigenous well-being, and especially the legacies of colonialism.

The first part of this call to action is relatively straightforward. Indeed, there is a growing body of scholarship being generated by Indigenous scholars and researchers working with Indigenous groups that is revealing links between Indigenous health disparities and factors related to 
colonization, dispossession, and intergenerational trauma (e.g., Adelson, 2005; Frohlich, Ross, \& Richmond, 2006; Richmond \& Ross, 2009). The second part of our call to action, whereby this research is drawn upon to better inform the design and practice of HIA and IBA negotiations, is less straightforward. As a starting point, better communication is needed between those who hold intimate knowledge of a community's health (e.g., nurses, social workers, etc.) and those who, respectively, author HIAs and negotiate IBAs. More radically, companies seeking to develop a mine or other resource development and governments charged with designing and overseeing review processes for such developments could recognize colonialism and other historical legacies as determinants of contemporary Indigenous health, and mandate IBA negotiators and HIA practitioners to consider explicitly how a particular development proposal might ameliorate or exacerbate these historical legacies. Such a shift is consistent with recent calls to develop alternative frameworks for understanding and mitigating health impacts associated with major resource developments, and to make use of ethnographic methods within HIA to incorporate better local histories and concerns (e.g., Jones et al., 2014). Another possible change in practice, which indeed has been undertaken by some Indigenous communities (see for example Marks et al., 2007; Parlee et al., 2007; Klinck et al., under review), would see communities develop community-relevant well-being indicators, which could be used to generate baselines in advance of development. These would not only provide a more comprehensive basis to measure development-related changes than is enabled by typical EA-mandated socio-economic baselines today, but also provide an effective means to identify community health priorities and issues of concern that community members evidently are keen to ameliorate.

As made evident in this article's two cases studies, IBAs and HIAs struggle to recognize and manage the impacts of colonialism on current Indigenous well-being. By identifying that what matters to Indigenous communities and what is captured in an IBA or HIA seldom coincide, we hope that we have provided an opportunity for all parties to consider a larger question. In the context of contemporary mine developments in northern jurisdictions and the assessment and management of their potential impacts, how can Indigenous community well-being, as influenced by the legacies of colonialism and assimilation policies, be understood and then translated into routine assessment metrics in an HIA and into items for negotiation within an IBA? Answering this question constitutes a significant task, but one that is evidently germane to many, including communities, industry, governments, and health and governance practitioners and researchers. Doing so will 
require a concerted effort to conceptualize how contemporary health and well-being is impacted by historical legacies and how governance processes can make room for issues that may be more reflective of past concerns than they are of a newly proposed project.

\section{Acknowledgements}

Jen Jones gratefully acknowledges and appreciates participation and review of the article by the Chickaloon Traditional Village Council and members of her MPH thesis committee. Ben Bradshaw gratefully acknowledges the research efforts and insights of Kelsey Peterson, Sophie Maksimowski, and Britania Twyee, and the co-operation of the residents and Council of the Hamlet of Baker Lake/Qamani'tuaq, and especially Robert Seeteenak, Assistant Senior Administrative Officer for the hamlet. Finally, both authors acknowledge Marie Puddister, cartographer at the University of Guelph; the assistance of two anonymous reviewers; and Deanna McLeod, managing editor of the Northern Review.

\section{Authors}

Jen Jones is a PhD student at the Department of Geography, University of Guelph and a 2015 Trudeau Scholar.

Ben Bradshaw is associate professor of geography at the University of Guelph.

\section{References}

Adelson, N. (2005). The embodiment of inequity: Health disparities in aboriginal Canada. Canadian Journal of Public Health, 96 Suppl 2, S45-61.

Barrett-Wood, Z., Knotsch, C., Davison, C., \& Bradshaw, B. (2012). Translating knowledge on impacts of mining for aboriginal community health: The issue of rotational two-week workshifts. Poster presented at the International Polar Year Conference, Montreal, April 22-27.

Bartlett, C., Marshall, M., \& Marshall, A. (2012). Two-eyed seeing and other lessons learned within a co-learning journey of bringing together indigenous and mainstream knowledges and ways of knowing. Journal of Environmental Studies and Sciences, 2(4), 331-340. doi: 10.1007/s13412-012-0086-8

Bhatia, R., \& Wernham, A. (2009). Integrating human health into environmental impact assessment: An unrealized opportunity for environmental health and justice. Ciência \& Saúde Coletiva, 14(4), 1159-1175.

Bradshaw, B., \& McElroy, C. (2014). Company-community agreements in the mining sector. In C. Louche and T. Hebb (Eds.), Socially responsible investing in the 21st century (pp. 173-193). Emerald Group Publishing Limited. 
Browne, A. J. (2005). Discourses influencing nurses' perceptions of First Nations patients. Canadian Journal of Nursing Research, 37(4), 62-87.

Cameron, M., Andersson, N., McDowell, I., \& Ledogar, R. J. (2010). Culturally safe epidemiology: Oxymoron or scientific imperative. Pimatisiwin, 8(2), 89-116.

Cameron, E. (2011). State of the knowledge: Inuit public health, 2011. National Collaborating Centre for Aboriginal Health.

Castleden, H., Crooks, V. A., Hanlon, N., \& Schuurman, N. (2010). Providers' perceptions of Aboriginal palliative care in British Columbia's rural interior. Health Social Care Community, 18(5), 483-491. doi:10.1111/j.1365-2524.2010.00922.x

Christensen, J., \& Grant, M. (2006). How political change paved the way for indigenous knowledge: The Mackenzie Valley Resource Management Act. Arctic, 60(2), 115-123.

Corburn, J., \& Bhatia, R. (2007). Health impact assessment in San Francisco: Incorporating the social determinants of health into environmental planning. Journal of Environmental Planning and Management, 50(3), 323-341.

Coulthard, G. (2014). Red skin, white masks: Rejecting the colonial politics of recognition. Minneapolis: University of Minnesota Press.

Cunsolo Willox, A., Stephenson, E., Allen, J., Bourque, F., Drossos, A., Elgarøy, S., \& Wexler, L. (2014). Examining relationships between climate change and mental health in the Circumpolar North. Regional Environmental Change, 1-14. doi:10.1007/s10113-014-0630-z

Douglas, M. J., Conway, L., Gorman, D., Gavin, S., \& Hanlon, P. (2001). Developing principles for health impact assessment. Journal of Public Health Medicine, 23(2), 148-154.

Frohlich, K. L., Ross, N., \& Richmond, C. (2006). Health disparities in Canada today: Some evidence and a theoretical framework. Health Policy, 79(2-3), 132-143. doi: 10.1016/j.healthpol.2005.12.010

Galbraith, L., Bradshaw, B., \& Rutherford, M. B. (2007). Towards a new supraregulatory approach to environmental assessment in Northern Canada. Impact Assessment and Project Appraisal, 25(1), 27-41. doi: 10.3152/146155107x190596

Gibson V. (2008). Negotiated spaces: Work, home and relationships in the Dene diamond economy (Doctoral dissertation, UBC, Vancouver).

Gibson, G., \& Klinck, J. (2005). Canada's resilient north: The impact of mining on aboriginal communities. Pimatisiwin, 3(1), 116-139.

Gibson, G., \& O'Faircheallaigh, C. (2010). IBA community toolkit: Negotiation and implementation of Impact and Benefit Agreements. Walter \& Duncan Foundation.

Gracey, M., \& King, M. (2009). Indigenous health part 1: Determinants and disease patterns. The Lancet, 374(9683), 65-75. 
Jones, J., Nix, N. A., \& Snyder, E. H. (2014). Local perspectives of the ability of HIA stakeholder engagement to capture and reflect factors that impact Alaska Native health. International Journal of Circumpolar Health, 73, 24411. doi: 10.3402/ijch. v73.24411

Kearney, M. (2004). Walking the walk? Community participation in HIA: A qualitative interview study. Environmental Impact Assessment Review, 24(2), 217-229.

King, M., Smith, A., \& Gracey, M. (2009). Indigenous health part 2: The underlying causes of the health gap. The Lancet, 374 (9683), 76-85.

Klinck, R., Bradshaw, B., Sandy, R., Nabinacaboo, S., Mameanskum, M., Guanish, M., Einish, P., Guanish, G., \& Pien, S. (under review). Enabling community well-being self-monitoring in the context of mining: The Naskapi Nation of Kawawachikamach. Engaged Scholar Journal, University of Saskatchewan.

Knotsch, K., Siebenmorgen, P., \& Bradshaw, B. (2010) Les 'Ententes sur les répercussions et les avantages' et le bien-être des communautés: Des occasions ratées? (Impact and Benefit Agreements and community well-being: A missed opportunity?). Recerches Amerindiennes au Quebec (Aboriginal Research in Quebec), 15(3), 59-68.

Kral, M., Idlout, L., Minore, J., Dyck, R., \& Kirmayer, L. (2011). Unikkaartuit: Meanings of well-being, unhappiness, health, and community change among Inuit in Nunavut, Canada. American Journal of Community Psychology, 48(3-4), 426-438. doi: 10.1007/s10464-011-9431-4

Kwiatkowski, R.E., Tikhonov, C., Peace, D.M., \&Bourassa, C. (2009). Canadian Indigenous engagement and capacity building in health impact assessment. Impact Assessment and Project Appraisal, 27(1), 57-67. doi: 10.3152/146155109X413046

Lapierre, D., \& Bradshaw, B. (2008) Corporate rationales for negotiating Impact and Benefit Agreements. Canadian Institute of Mining, Metallurgy and Petroleum Annual Meeting Technical Program.

Lavallee, L. F., \& Poole, J. M. (2010). Beyond recovery: Colonization, health and healing for Indigenous people in Canada. International Journal of Mental Health and Addiction, 8(2), 271-281.

Maksimowski, S. (2014). Well-being and mining in Baker Lake, Nunavut: Inuit values, practices and strategies in the transition to an industrial economy. (Unpublished master's thesis, University of Guelph, Guelph).

Marks, E., Cargo M., \& Daniel, M. (2007). Constructing a health and social indicator framework for Indigenous community health research. Social Indicators Research, 82(1), 93-110.

MacNaughton, G., \& Hunt, P. (2009). Health impact assessment: The contribution of the right to the highest attainable standard of health. Public Health, 123(4), 302-305.

Nadasdy, P. (2012). Boundaries among kin: Sovereignty, the modern treaty process, and the rise of ethno-territorial nationalism among Yukon First Nations. Comparative Studies in Society and History, 54(03), 499-532. 
Napoleon, H. (1996). Yuuyaraq: The way of the human being. Fairbanks, Alaska: Alaska Native Knowledge Network.

NIRB. (2013). Meadowbank gold project annual report 2012 - Appendix K1: Developing community wellness indicators in the Hamlet of Baker Lake. Accessed on Nunavut Impact Review Board website, Feb 12, 2015.

Noble, B., \& Bronson, J. (2006). Practitioner survey of the state of health integration in environmental assessment: The case of northern Canada. Environmental Impact Assessment Review, 26(4), 410-424.

Noble, B., \& Birk, J. (2011). Comfort monitoring? Environmental assessment follow-up under community-industry negotiated environmental agreements. Environmental Impact Assessment Review, 31(1), 17-24.

O'Faircheallaigh, C. (2012). International recognition of indigenous rights, indigenous control of development and domestic political mobilisation. Australian Journal of Political Science, 47(4), 531-545.

Paci, C., \& Villebrun, N. (2005). Mining Denendeh: A Dene Nation perspective on community health impacts of mining. Pimatisiwin, 3 (1), 71-86.

Painter, J., Fuller, S., \& Atkinson, S. (2012). Well-being and place. Farnham, Surrey, England: Ashgate.

Parkes, M. (2011). Diversity, emergence, resilience: Guides for a new generation of ecohealth research and practice. EcoHealth, 8(2), 137-139. doi: 10.1007/ s10393-011-0732-8

Parlee, B., O'Neil, J.D., Lutsel K'e Dene First Nation. (2007). The Dene way of life: Perspectives on health from the Canadian North. Journal of Canadian Studies, 41(3), 112-133.

Parlee, B., \& Furgal, C. (2012). Well-being and environmental change in the Arctic: A synthesis of selected research from Canada's International Polar Year program. Climatic Change, 115(1), 13-34. doi: 10.1007/s10584-012-0588-0

Parry, J. M., Kemm, J. R., \& on behalf of all participants of the Evaluation of Health Impact Assessment Workshop. (2005). Criteria for use in the evaluation of health impact assessments. Public Health, 119(12), 1122-1129. doi: 10.1016/j. puhe.2005.05.002

Parry, J., \& Stevens, A. (2001). Prospective health impact assessment: Pitfalls, problems, and possible ways forward. BMJ: British Medical Journal, 323(7322), 1177-1182. Retrieved from http://www.jstor.org.proxy.consortiumlibrary.org/ stable/25468319

Parry, J., \& Wright, J. (2003). Community participation in health impact assessments: Intuitively appealing but practically difficult. Bulletin of the World Health Organization, 81(6), 388.

Peterson, K. C. (2012). Community experiences of mining in Baker Lake, Nunavut (Unpublished Master's thesis, University of Guelph, Guelph). 
Prno, J., \& Bradshaw, B. (2008). Program evaluation in a northern aboriginal setting: Assessing Impact and Benefit Agreements. Journal of Aboriginal Economic Development, 6(1), 61-77.

Reading, C. L., \& Wien, F. (2013). Health inequalities and the social determinants of Aboriginal peoples' health. National Collaborating Centre for Aboriginal Health, Prince George, BC.

Richmond, C. A. M. (2009). The social determinants of Inuit health: A focus on social support in the Canadian Arctic. International Journal of Circumpolar Health, 68(5), $471-87$.

Richmond, C. A. M., \& Ross, N. A. (2009). The determinants of First Nation and Inuit health: A critical population health approach. Health $\mathcal{E}$ Place, 15(2), 403-411. doi: http://dx.doi.org/10.1016/j.healthplace.2008.07.004

SEMC. (2013). Annual Report of the Kivalliq Socioeconomic Monitoring Committee (http://www.nunavutsemc.com/Kivalliq).

Shandro, J. A., Veiga, M. M., Shoveller, J., Scoble, M., \& Koehoorn, M. (2011). Perspectives on community health issues and the mining boom-bust cycle. Resources Policy, 36(2), 178-186. doi: 10.1016/j.resourpol.2011.01.004

Siebenmorgen, P., \& Bradshaw, B. (2011). Re-conceiving Impact and Benefit Agreements as instruments of Aboriginal community development in northern Ontario. Oil, Gas, Energy Law Intelligence, 4.

Smylie, J. (2009). The health of aboriginal peoples. In D. Raphael (Ed.), Social determinants of health (pp. 280-301). Toronto: Canadian Scholars' Press Inc.

Sotero, M. (2006). A conceptual model of historical trauma: Implications for public health practice and research. Journal of Health Disparities Research and Practice, 1(1), 93-108.

State of Alaska,HIA Program. (2011). Technical guidance for health impacts assessment (HIA) in Alaska.

Wernham, A. (2011). Health impact assessments are needed in decision making about environmental and land-use policy. Health Affairs, 30(5), 947-956.

Winkler, M. S., Krieger, G. R., Divall, M. J., Cissé, G., Wielga, M., Singer, B. H., Tanner, M. \& Utzinger, J. (2013). Untapped potential of health impact assessment. Bulletin of the World Health Organization, 91, 298-305.

Wismar, M., Blau, J., \& Ernst, K. (2007). Is HIA effective? A synthesis of concepts, methodologies and results. In The effectiveness of health impact assessment. Scope and limitations of supporting decision-making in Europe (pp. 15-33). Copenhagen: WHO Regional Office for Europe. 